\title{
The Concept and Development Strategies of the Primary Teachers' Practical Knowledge
}

\author{
Chen Na \\ Education and Science Department, Early-childhood Education, Hubei University of Education, Wuhan, China
}

\section{Email address:}

wendycn08@163.com

\section{To cite this article:}

Chen Na. The Concept and Development Strategies of the Primary Teachers' Practical Knowledge. Teacher Education and Curriculum Studies. Vol. 6, No. 3, 2021, pp. 94-100. doi: 10.11648/j.tecs.20210603.14

Received: August 8, 2021; Accepted: August 30, 2021; Published: September 6, 2021

\begin{abstract}
Teachers' practical knowledge (TPK) has become a research field of teacher education, but it has not been paid enough attention in the early stage of its formation, which is not conducive to the comprehensive and in-depth study of the development of TPK. The purpose of this study is to arouse enough attention of normal university students to acquire TPK, and to have a tool for in-depth analysis of the quality of TPK. This study mainly uses documentary method. By combing existing studies, this paper points out the disadvantages of naming TPK as the same as the stage of teachers' professional development, and demonstrates the necessity of putting forward the concept of Primary Teacher's Practical Knowledge (PTPK). It believes that PTPK has its own value and may be owned by all teachers, rather than the exclusive label of ordinary students and novice teachers. This paper describes and demonstrates the connotation, characteristics and value of PTPK based on a three-dimension framework which composed of representation, structure and level. PTPK truly needs to be optimized but neither in a linear way nor static superposition of experience, instead of diversified in representation form. From the dynamic perspective of the generation mechanism of TPK, this paper puts forward two development strategies of PTPK with the nature of "deliberation": one is to criticize the PTPK temporarily away from the situation via explicit the PTPK in three representation, guide interns in a systemic structure and teach the theoretical courses focus on cultivating higher thinking; the other is to put it back in the context for testing by creating both virtual and real situations.
\end{abstract}

Keywords: Teachers' Practical Knowledge, Primary Teachers' Practical Knowledge, Normal University Students, Majoring in Early Childhood Education, Reflective-on-Action

\section{Introduction}

With the professionalization of teacher profession, teacher practical knowledge (TPK) has been paid more and more attention by teacher educators, and gradually developed into a research field [1]. Existing researches have provided abundant theoretical resources for the definition, composition, characteristics, source, generation and significance of practical knowledge [2]. However, at present, more attention is paid to the practical knowledge of experienced teachers than to normal students or novice teachers [3]. Researches on the development of TPK are mostly placed in the frame of teacher professional development stage. So is TPK "whole" or "none"? Is it appropriate to name the development stage of TPK same as the stage of teacher professional development? What is the nature or characteristic of TPK in its initial period? These issues are yet to be explored and articulated.

\section{The Origin of the Concept of TPK}

\subsection{The In-depth Study of TPK Needs to Distinguish “Knowledge" from "Owner"}

TPK refers to the understanding of education and teaching that teachers truly believe in and actually use and/or show in their teaching and education practice [4] (p. 106). According to the degree of clarity of teachers' awareness and expression of their practical knowledge, TPK can be divided into several levels: the expressible, the aware but inexpressible (tacit or tacit elements), and the unconscious (implicit theory) [5]. The "speakable" is only the tip of the iceberg of TPK each individual possesses; "Conscious but unspoken" and "unconscious" make up the majority [6]. As the saying goes, "Rome wasn't built in a day," how did the iceberg of TPK 
come into being? From a macro perspective, FAN Lianghuo proposes that there are three main sources of TPK: learner experience, pre-service training experience and on-the-job experience [7] (p. 47-51). It can be seen that as long as one has experienced the "teaching situation", no matter whether he/she is a "teacher" or a "student" in the situation, he/she is likely to acquire the practical experience that constitutes TPK Some scholars believe that TPK not only comes from the accumulation and understanding of teachers' personal experience (direct experience), communication and cooperation between peers (indirect experience), but also from the understanding, application and expansion of theoretical knowledge [4] (p. 106).

From the perspective of knowledge management, the tacit or implicit part of TPK can be understood and shared through "display", also known as "explicit tacit knowledge" mode [8]. In this process, practical knowledge must be temporarily separated from its "Knower", refers to the individual teacher with TPK, and new TPK is generated after "dialogue" with community members. It can be seen that in order to study TPK deeply and comprehensively, it is necessary and possible to distinguish it from teacher (owner) temporarily.

\subsection{The Pros and Cons of Naming the Development Stage of TPK Same as the Stage of Teacher Professional Development}

The current research on the development of TPK generally refers to the framework of teacher professional development stage, and uses typical teaching behaviors of teachers as the characteristics of TPK being "in a certain stage". For example, ZHAO Chang-mu put forward three stages: the lack of teaching at the beginning, the gradual enrichment after teaching, and then the "plateau period" adjustment and continuous growth [9]. Lin Tinghua from Taiwan named "practical knowledge in the exploration period" from the following six attributes obtained after he coded the observation and interview data of three novice teachers: Using old experience, paying attention to their own needs, seeking opinions, feeling frustrated, lacking confidence, and being forced to lead classes [10]. In recent years, some mainland researchers believe that "taking classes is the basis for normal university students to acquire TPK, and the teaching process is most easily mastered by normal university students, which is the characteristic of the initial stage of TPK."[11]. Obviously, the attributes or characteristics mentioned by the last two are not so much the characteristics of "practical knowledge in the groping period" as the behavioral characteristics and subjective feelings of teachers (knowledge owners) in the groping period.

There are two logical loopholes in using the stage of teacher professional development to name the stage of practical knowledge development:

\subsection{1. “Teacher Professional Development" and TPK Are Not in the Same Category}

"Teacher professional development" is an important concept in teacher education. The orientation aiming at developing teacher's professional competence is called "professional development" [12]. It "refers to both the process of teacher's professional development and the process of promoting teacher's professional development (teacher education).'[13] Numerous relevant studies have found that teacher's professionalism (such as teaching knowledge) does not necessarily increase with the increase of teaching experience [7] (p. 214). The most obvious example is that there is a "plateau" in the stage of teacher professional development, which generally occurs in the "mature" stage of teachers who have accumulated many teaching experience. However, due to the lack of internal motivation, it stagnates in the "career plateau" and produces "job burnout".

TPK is a sub-concept under the concept of "teacher's knowledge", which is used to emphasize the professionalism of the teacher profession. In any case, it is difficult to name the impressive morphology of TPK, which described by many current researches on the TPK of experienced teachers or excellent teachers in the teaching situations by "plateau maturity period" [14].

In addition, the premise of referring to the characteristics of TPK development with the stage of teacher professional development is that "the development of TPK has stages". The proposition is not self-evident. However, few researchers have come up with solid arguments. Therefore, no matter from the perspective of knowledge development or knowledge management, it is not appropriate to classify and name the stages of TPK development corresponding to the stages of teacher professional development.

\subsubsection{Confuse the Two Concepts of "Professionalism" and "Specialization" of Teachers}

"Professionalization" is a sociological concept. "Teacher professionalization" is a type of professional professionalization, which refers to the process of realizing the strategies and means to improve the social status, income and working conditions of the teacher profession [15]. According to some researchers, the main purpose of proposing the concept of TPK is to "promote the professional development of teachers", which claims to link TPK with "teacher professionalization" rather than "teacher professional development" [16]. TPK can highlight the "professional" level of teachers to a large extent, and become the knowledge foundation of teacher's professional development; it even plays an extremely important role in the field of teacher "professionalization", such as becoming a critical weapon to empower teachers and providing constructive tools for teacher's professional development [4] (p. 109). But it does not constitute the whole of "teacher professional development". At least, another process that determines "teacher professional development" -"promoting teacher professional development" does not completely correspond to the process of TPK development in terms of stages.

Therefore, it is acceptable to name the initially formed TPK with the names of the stages of teacher professional 
development such as "survival period" or "exploration period" as a transitional concept or an expedient. However, it has neither guiding significance for normal universities to realize the training Objectives of "application-oriented talents with certain TPK", nor for pre-service teacher's training of "acquiring TPK".

\section{The Conceptual Definition of Primary TPK}

\subsection{A Descriptive Definition of Primary TPK}

TPK is grounded in practical experience, triggered by the "dilemma", and gradually forms a relatively stable educational belief and other contents in the "dilemma space" [17]. Inspired by the key concept of "legitimate marginal participation" which proposed by J Leif and E Winger, we call Primary TPK those TPK that is based on a small amount of practical experience, but needs to be diversified in representation form, rich in content, and in-depth in reflective level.

The term "primary" here is not a stage that implies "not good enough" within the framework of the linear path of "primary - intermediate - high". On the contrary, it is a positive term with a dynamic nature, as opposed not to "advanced" but to "non", "non-practical knowledge"; Primary here emphasizes "empowerment", which "implies an open access, an increasing access to the source of access for the purposes of understanding." [18].

Accordingly, believing that the development of practical knowledge is not phased; Primary teachers' practical knowledge (PTCK) is widely available to all teachers, rather than being the exclusive label of normal students and novice teachers. When senior teachers or even excellent teachers are faced with disciplines that they have never set foot in or practice fields that require them to "learn from scratch", they have to try and make mistakes in various methods and accumulate practical experience. In this case, their TPK has the characteristics of PTCK.

\subsection{Analysis Dimension and Characteristic of PTPK}

\subsubsection{Representation}

Inspired by the Italian education reformer Loris Malaguzzi's view that "children have one hundred languages", TPK, which is difficult to be presented by proposition, has its own unique "language" to express. Chen Xiangming research team divided the representation forms of TPK into three categories: schema (image, metaphor), action (formalization, action formula), speech (narrative, case) [19]. For example, when teaching the concept of area, the teacher asks students to touch the area of the book, the area of the blackboard, the area of the door, etc. The teacher use these "body-oriented" feelings to give students a deeper understanding of abstract mathematical concepts [20].

According to the analysis of the practice logs of early-childhood education majors, it is found that the representation characteristics of PTPK are mainly speech, less schema and action. The total content is not rich. The verbal representations include fragmentation, "running account", morality, etc., either they only tell stories without connotation, or they talk about "meaning" and "principles" has nothing to do with the problem situation.

\subsubsection{Structure}

About the "structure" of TPK, there are roughly three analysis perspectives: one is the composition; Second, content dimension; The third is the constituent elements.

The "component" perspective is a traditional, static perspective. Since Shulman put forward the concept of teacher's knowledge, many researchers at home and abroad have taken it as the framework to analyze teaching content knowledge (PCK) and even TPK. At present, domestic researchers mostly adopt the "six-component theory", namely: teacher's educational belief, self-knowledge, interpersonal knowledge, situation knowledge, strategic knowledge and reflective knowledge [4] (p. 106).

Chinese researchers using big data in different group of TPK "six elements" comparison, discovered the main ingredients has significant difference: the low level of TPK is the most important ingredients of interpersonal knowledge, situation knowledge and self knowledge, etc., main ingredients are thinking knowledge, lack of education beliefs and strategies of knowledge; It is found that the TPK community of low-level teachers presents many isolated nodes, in which there is no strong connection between "teaching" and "learning", and the knowledge structure is relatively loose [21]. The findings of this study can be regarded as the characteristics of PTPK in the sub-dimension of "component structure".

The perspective of "content" mostly takes "practice situation" as the dividing standard. For example, a researcher divides the TPK structure of preschool normal university students into five dimensions: daily life organization of children, early childhood research, self-cognition, environmental interaction, and early childhood development, centering on "responding to the relatively stable strategic understanding system of 'how to do' generated in the practice field of early childhood education". It is found that the overall development of TPK of pre-service preschool teachers is good, but the development level of each dimension is unbalanced [22] (p. 74-75). This research result may be used as a reference for the "content" characteristics of the PTPK based on the nursery education situation.

From the perspective of "structural elements", the four basic elements of TPK are: subject, problem situation, reflection in action and belief [23]. Among them, the "problem situation" is the triggering mechanism, the reflections in the "action" is a TPK of the "matrix", "main body" to take action to get to know and experience a Dewey in the sense of "experience" and "belief" is a reflection after the "action" and was promoted to a stable can guide the subject about education values and code of conduct for the follow-up actions. Since TPK is not necessarily universal 
[24], it is difficult to judge the TPK acquired based on "situation" and "reflection" from this perspective. Since "reflection" is a relatively mature concept. Therefore, the two elements of "reflection in action" and "belief" in this sub-dimension will describe the corresponding characteristics of PTPK in the next analytical dimension by combing the reflective level.

\subsubsection{Level}

Since Schoen put forward the "reflective practitioner", "reflection" has been regarded as the internal mechanism of the generation of TPK. According to the theories of P. M. King and K. S. Kitchener, ZHAO Chang-mo proposed the "five-level theory of belief system development" as TPK, namely, the untested acceptance, the authority firmly believed by the individual perspective, the "quasi-counter-thinking" stage, the "reflective thinking stage" and the "final stage" [25].

Barbara Larrivee proposed the "four levels of reflection theory". From the core to the periphery are: Philosophical level, personal theory level, interpretation level, decision-making level, etc. [26] (see Figure 1 for details).

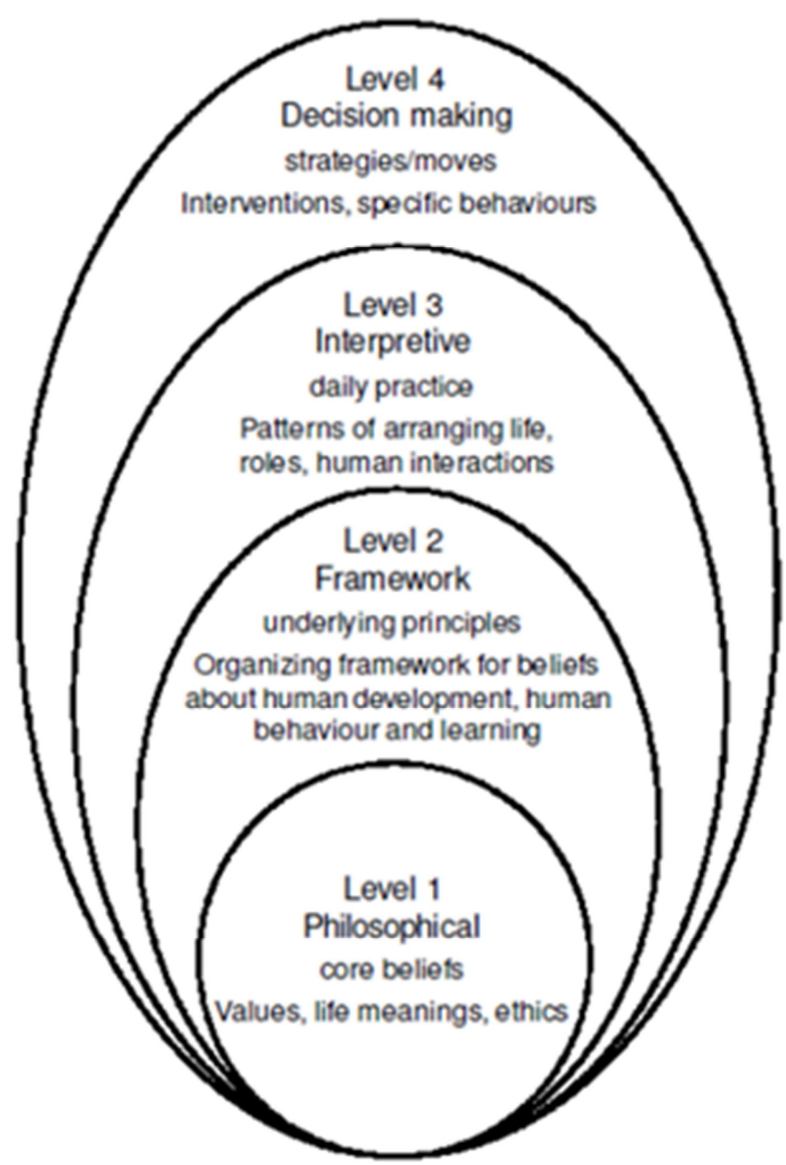

Figure 1. Barbara Larrivee "Four Levels of Reflection".

In the initial level of TPK, there are more situation knowledge and interpersonal knowledge, but less educational belief knowledge. It can be seen that the reflective level is mainly in the decision-making and interpretation level of the outer layer of the manifestation, and it is difficult to reach the implicit principle level, and it is harder to reach the philosophical level of the deep center. It can be said that the level of teacher's individual reflection determines the level of their TPK.

\subsection{The Unique Value of PTPK}

\subsubsection{Primacy Effect}

TPK to form a "critical period", despite the "critical period" of the specific time has not yet been agreed, [now about the "critical period" of practical knowledge of the specific formation there are at least three views: (1) the four-year students of junior grade; (2) during the period of graduation practice; (3) induction within two years after the novice teachers. But there is no doubt that the "critical period" results in PTPK. "The TPK that is formed has a primacy effect that affects the future.... Practical knowledge, once formed, acts as a filter for future external information." [27].

\subsubsection{Unfinished}

The traditional view of children believes that children are incomplete, so they should spend their childhood as soon as possible; But Dewey saw a kind of self-growth power in this "incomplete nature". The Incompleteness of PTPK also means that it has self-directed growth power, which will encourage normal university students to acquire more practical experience and become more perfect TPK through reflection and examination.

\section{The Development Strategies of PTPK}

\subsection{Analysis Perspective and Unit of PTPK Development}

\subsubsection{Dynamic Perspective: Generative Mechanics}

There are numerous existing studies that put forward corresponding development strategies for influencing factors of TPK. In our opinion, "static perspective+" repair "approach" cannot effectively solve the problem of PTPK development. Because from the static perspective of influencing factors, the way or characteristics of interaction between influencing factors and TPK as a "whole alloy" have not been touched, it is more difficult to pay attention to the law of interaction among multiple influencing factors and then influence the development of TPK. "Generative mechanism" is a dynamic perspective to investigate TPK, which is more conducive for researchers to fully grasp the process of initial practical knowledge from "nothing" to "being".

\subsubsection{Unit of Analysis: Key Activities}

Based on the culture-historical activity theory, some researchers selected three typical situations: classroom teaching, teaching and research group practice, and practice of heterogeneous teacher community, and correspondingly proposed three generation mechanisms of practical knowledge: embedded model generation, extended generation and circular generation [20] (p. 53-203). The three types of situations and mechanisms all include the process of "interaction-negotiation" and "knowledge sharing". This 
shows that TPK is not acquired by individual teachers "thinking hard", but by group interaction (even in the classroom teaching situation, the teaching group is composed of teachers and students). Among them, the most important condition is "reflection", which is the core connecting other elements of TPK structure and finally forming "new belief".

Based on reflection, the generation of TPK in group interaction is a process with the nature of "deliberation" [23, 20-22], which includes two key activities: "criticism that temporarily pulls practical knowledge out of the situation" and "test it again in the situation". Thus constitutes a cycle of improving practical experience to TPK and back to extended practical experience to new TPK.

\subsection{Optimization Strategies of PTPK}

\subsubsection{A PTPK Critique Temporarily Detached from the Situation}

A manifestation or demonstration of PTPK. The carrier and result of the PTPK manifest, namely the three "representations" mentioned above: schema (image, metaphor), action (formalization, action formula), speech (narrative, case). Some researchers suggest to "encourage normal university students to actively communicate and discuss with their supervisors" [21] (p. 78) to promote them to acquire TPK. This is actually a strategy to make PTPK explicit by means of verbal representation. In addition, normal university students should also be encouraged to use schema and action representations, such as timely record of various educational phenomena and events that arouse their interest and concern, as well as the resulting thoughts and opinions. Encourage interns to observe each other and record videos to capture PTPK of action.

A structured practice path for the system. Normal university students' criticism of PTPK often miss the point because they lack of adequate "database", a concept found in Schon's analysis of examples, images, understandings, and actions of "reflective internships" conducted by designers, psychologists, and other experts but not interns [35] (p. 63-137, 215-230). However, it is difficult to identify their guiding value to the subsequent practice situation, which is why their reflections often fail to grasp the point. Some studies have proposed "systematic structured practice guidance path" to deal with the strong randomness and lack of systematic practice guidance [28]. There are four steps: The first is interview -- to determine the starting point of PTPK; the second is after-class reflection -- to reflect on the PTPK with the help of the real teaching behavior just finished; the third is questioning -- to make those teaching behaviors (action type PTPK) that are not helpful to "learning" appear through questioning. Fourth, check -- find the gaps and core beliefs in the PTPK by writing the teaching reflection. Obviously, these four steps not only implicitly conform to the mode of "explicit tacit knowledge", but also follow the path of "reflection" from the most superficial "decision-making level" to "explanation level", to "framework level" and even to the core "philosophy level", which is from the outside to the inside, from the explicit to the implicit.

The teaching of theory courses with the cultivation of advanced thinking as the core. The essence of the criticism that temporarily removes the PTPK from the situation is "reflection after action". The quality of "criticism" is highly correlated with "reflective ability", which consists of understanding, critical thinking and creative thinking, should be the most important goal of pre-service theoretical course teaching. Some researchers put forward that China's normal universities should adopt a practical orientation in the teaching of theoretical courses [29]. This view is open to debate. Extension of the practical hour to the theoretical courses, or adding the so-called "Experiential the theory" such as case analysis, is most likely to increase the practical experience or fragmentary conceptual schema of normal university students, but may not promote the development of PTPK. Some researchers have already found that the "blind practice" of only pursuing the attainment of practical course hours and credits, or taking the "sheep-shepherding" management to keep students in kindergarten for a semester, will lead to the lack of TPK of kindergarten teachers in the future [30].

Schwab divides disciplinary knowledge into substantive knowledge and syntactical knowledge, which respectively refer to "the knowledge of concepts connected within a discipline" and "the methods used to construct knowledge within a discipline" [31] (p. 5). Based on this classification, Schulman and Grossman put forward the concept of "Content knowledge" [31] (p. 9) or "Subject matter knowledge" [7] (p. 16). Under this conceptual framework, the basic concepts, basic principles and basic theories in the theoretical courses offered by normal universities can be attributed to "substantive knowledge", and the method to obtain these basic concepts, basic principles and basic theories is "grammatical knowledge". The reason why some interns think that "pedagogy or psychology and other fundamental knowledge learned in college are 'useless' or 'of little effect' in practice", while others recognize the fundamental knowledge $[32,33]$, the core reason is not the disconnection between theoretical knowledge and practice, but the fact that in the process of learning theoretical knowledge, teachers only pay attention to students' mastering of "substantive knowledge" but ignore their acquisition of "grammatical knowledge".

Subjects of theory curriculum, therefore, normal colleges and universities should highlight mastery of "grammar knowledge", which will not only basic concept, basic principle and basic theories such as the core content of course and the basis of TPK, but also as a normal to obtain higher-order thinking methods and tools, will originally hours used to guide the student to analyze and criticize "substantive knowledge" of the courses, scar-fold students obtain TPK in the practice school or kindergarten benefited from their solid grasp "grammar knowledge".

\subsubsection{Put PTPK Back into Context}

The ultimate purpose of displaying or making explicit the 
PTPK is "if it is consistent with the purpose of knowledge or practice, it will be utilized and preserved; If it is not consistent with the purpose of knowledge or practice, then it can also be limited and rejected." [34]. Putting PTPK in context requires "reflection-in-action". Inspired by Schon's "structures reflected-in-action", we divide the situations in which PTPK is tested into "virtual situations" and "real situations".

Virtual situation: A field experiment of PTPK in an "improvisation game". A virtual situation is considered a rehearsal, role play, or improvisation game [35]. The biggest advantage of using virtual situation to test PTPK lies in three aspects: low cost, reproducibility and harmlessness to educational objects. Frequent participation in virtual situation activities can enrich the "database" of PTPK.

Taking normal university students majoring in preschool education as an example, virtual situations mostly occur in the process of completing practical course tasks, represented by the activity design or simulated teaching scenes under the guidance of teachers. For example, the middle class designed by students and simulated the implementation of the "understanding graphics" math collective teaching activities, a student as the "teacher", the group of other 6 students play 4-5 years old children. The "teacher" is ready to begin the "class". After a long silence, she asked, "Do you want to play a game?" "YES!" "So today we will play a game, OK?" "Good!" "I brought a lot of interesting graphics today, look, what is this graphic?" "Circle, square,..." Although in the interpretation link, students mentioned the strategy of "using open questions to arouse children's existing experience" (oral practical knowledge), when she entered the simulated "teaching" situation, the questions she asked were almost meaningless "closed-ending". In the reflection and evaluation of the simulation activity, the students who participated in the observation pointed out the shortcomings of the lead-in link. The "teacher" said, "I know I should ask an open question, but I was so nervous that I completely forgot what to say and my mind went blank. Just remembered that 'play a game' is important, and said a few words casually. Be careful next time."

Obviously, virtual-reality can distinguish which is the subject of "know" but has not been internalized in the PTPK (in the example above is "use open-ended questions to raise children experience"), which is the main body "used" but did not be tested or needs to be fixed in the PTPK (in the example above is "play a game at any time is suitable for"); In the peer discussion, the student realizes that she should use the "known" TPK to guide her own practice, which provides necessary conditions for the expansion of the PTPK.

Real situation: Examine and expand PTPK through "decision and action". Western teacher educators propose that in order to make teaching more accurately and effectively conceptualized, teachers can be regarded as "decision makers". Naturally, no matter what decisions teachers make, the premise must be "adopting certain standards (educational beliefs) + rational judgment (reflection)" [36], that is, the application and generation of TPK.
Therefore, the detection of the PTPK in the real teaching situation can be operated as: recording and analyzing some decisions made by the subject, especially the decisions made by the subject in the "dilemma" event; Ask the "criteria" and "judgment" behind the decision; What did he/she think was "meaningful" at the time? Do you still think it makes sense? What has changed its standards? (see Figure 2).

As the unclear or unstable educational beliefs in the PTPK are constantly thought and adjusted and gradually become clear and stable, the criteria that influence the subject to make decisions will be gradually automated by "deliberately remembering". This is the ideal state of using real situation to promote the development of PTPK.

\section{Conclusion}

It is not a best selection to name the development of TPK refers to the framework of teacher professional development stage. TPK truly needs to be optimized but not in a liner way, instead of diversified in representation form. That's why PTCK is widely available to all teachers, rather than being the exclusive label of normal students and novice teachers. There are at least three dimensions to analyse PTPK: representation, structure and level. In order to improve the quantity and quality of PTPK, presenting, structural guiding and teaching for higher thinking are needed as well as creating both virtual and real situations for testing.

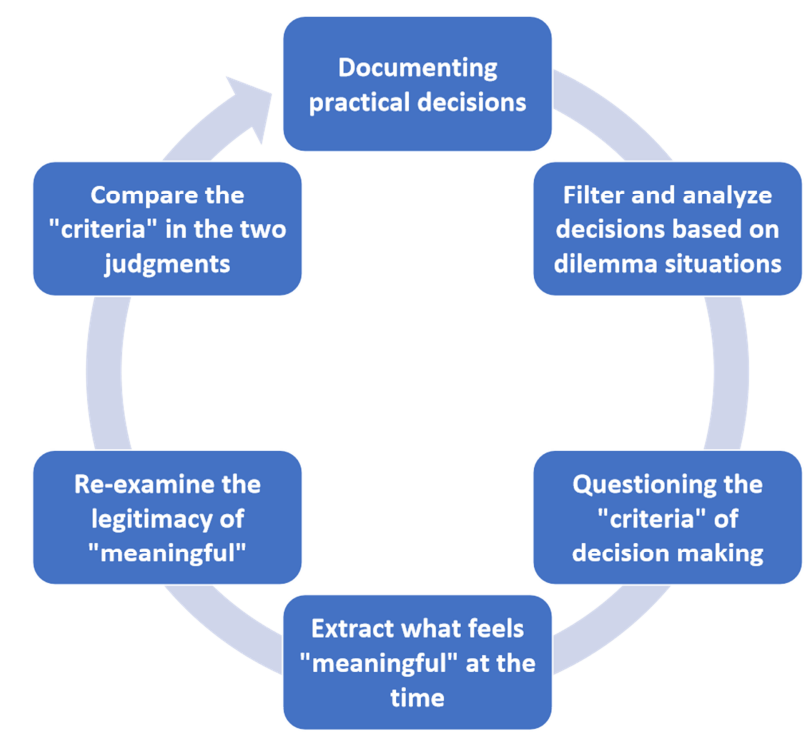

Figure 2. Schematic diagram of testing PTPK in real teaching situation.

\section{Acknowledgements}

This research was supported by a grant from Ministry of Education youth Project of the National Education Science Planning Project (EHA210422) and a grant from horizontal subject (ESHX20210039).

In addition, this study also thanks to the guidance of Professor Lin Jincai (Tainan University, Taiwan) and Professor Xia Zhengjiang (Shanghai Normal University). They gave a very professional opinion. 


\section{References}

[1] WEI Ge, CHEN Xiangming. (2018) The Emergence and Development of Research on Teacher Practical Knowledge. Journal of East China Normal University (Educational Science), 36 (06), 107-109.

[2] WU Yichang. (2007) A review of teacher's practical knowledge in China. Shanghai Education and Research Institute, 11, 15-19.

[3] CHEN Hongjie. (2018) Three Questions on the Study of Teachers' Practical Knowledge. Peking University Education Review, 16 (04), 11-19.

[4] CHEN Xiangming. (2003) Practical Knowledge: the Knowledge Base of Teachers' Professional Development. Peking University Education Review, 1.

[5] JU Yucui. (2003) Teacher education and the renewal of teacher personal practice theory. Education Exploration, 3, 92-94.

[6] ZHANG Minxuan. (2002) Explicit professional knowledge and teacher professional development. Educational Research, 01, 14.

[7] FAN Langhuo. (2013) Research on the development of teachers' teaching knowledge (Second edition). East China Normal University Press.

[8] Hirotaka Takeuchi, Ikujiro Nonaka. (2018) The Spiral of knowledge creation: Knowledge management theory and case studies. Intellectual Property Publishing House, 47-70.

[9] ZHAO Changmu. Teacher Growth Formation and Development of Practical Knowledge and Intelligence. Educational Research. 5, 54-58.

[10] LIN Tinghua. (2015) A study on the practical knowledge development of senior preschool teachers. Journal is being built (Taiwan), 28, 277.

[11] CHEN Shuang. (2017) Features of Student Teacher's Practical Knowledge at the Initial Stage of the Practicum. Foreign Languages and Their Teaching, 4, 34.

[12] Quote in ZHU Xiaoman. (2001) Talk about "Teacher professional Growth". Journal of Nantong University (Social Sciences Edition), 3, 90.

[13] PENG Bin. (2012) Achievement professional preschool teachers -- A study of preschool teachers professional Development stage. Peking Normal University Press, 13.

[14] LI Dan. (2011) On the Development to Preschool Teachers' Practical Knowledge. Southwest university, 92.

[15] LU Naigui, WANG Xiaoli. (2008) Analysis of the Profession Dimension in Theory of Teacher Professional Development. Teacher Education Research, 11, 2.

[16] ZOU Bin, CHEN Xiangming. (2004) Tracing to the Source of the Concept of Knowledge for Teachers. Curriculum, Teaching Material and Method, 6, 106.

[17] WEI Ge, CHEN Xiangming. (2017) How to Capture Teachers' Practical Knowledge - Path Exploration and Practical Demonstration in "Dilemma Space". Educational Science Research, 2, 83.

[18] Jean Lave, Etienne Wenger. (2004) Situational learning: Legitimate Peripheral Participation. East China Normal University Press, 6-7.
[19] CHEN Xiangming. (2018) Revisiting Teacher Practical Knowledge: A Response to Some Queries. Peking University Education Review, 16 (4), 22.

[20] WEI Ge. (2020) Generation of Teachers' Practical Knowledge. Educational Science Publishing House, 87.

[21] Wang Lu, Peng Le, Li Yao, Ren Yi. (2019) The Characteristics of Excellent Teachers' Practical Knowledge: Knowledge Discovery Based on Big Data. Curriculum, Teaching Material and Method, 2, 128.

[22] DAN Fei, HE Jingwen, ZHANG Mengtao. (2019) Development of Practical Knowledge in Pre-service Preschool Teachers: Current Situation, Influencing Factors and Educational Suggestions. Educational Research and Experiment, 7, 74-75.

[23] CHEN Xiangming. (2009) On the Constituting Components of Teachers' Practical Knowledge. Educational Research, 10, 68.

[24] LU Lijie. (2007) Reflection on Teacher's Practical Knowledge Study and Its Enlightenment. Research in Educational Development, 11B, 22.

[25] ZHAO Chang-mu. (2002) Continuous teacher growth: Faith change and Adaptation. Global Education, 8, 22-24.

[26] Barbara Larrivee. (2000) Transforming Teaching Practice: Becoming the Critical Reflective Teacher. Routledge: Taylor \& Francis Group, 302.

[27] LI Dan. (2011) On the Development to Preschool Teachers' Practical Knowledge. Southwest university, 86.

[28] CHEN Hong. (2018) Structural Practice Guidance: Construction of New Teachers' Educational Knowledge. Journal of Beijing Institute of Education, 5, 16-19.

[29] HUANG You-chu. (2013) The Missing and Improvement of Pre-service Teachers' Practical Knowledge. Teacher Education Research, 28 (05), 85.

[30] LIU Tian-e. (2016) The Problems Existing in the Curriculum of Preschool Teacher Education in Colleges and Universities and the Way of Reform. Education Review, 10, 118.

[31] Lee S. Shulman. Those who understand: Knowledge growth in teaching. Educational Researcher, Feb., 1986, Vol. 15, No. 2 (Feb., 1986), 4-14.

[32] QU Xia. (2012) Student Teachers' Perceptions of Theoretical Knowledge in Field Experience and Its Implication for Pre-service Teacher Education. Teacher Education Research, 6, 15-16.

[33] JIANG Shuling, LI Mengyao. (2016) Transformation from Theoretical Knowledge to Practical Knowledge-A Perspective of Professional Capability Development of Student Teachers. Education Research Monthly, 6, 73.

[34] SHI Zhongying. (2001) Tacit knowledge and Normal Education. Teacher Education Research, 3, 36-40.

[35] Donald A. Schön. (2007) The Reflective Practitioner: how professionals think in action (Chinese edition). Educational Science Press.

[36] Timothy G. Reagan, Charles W. Case, John W. Brubacher. (2005) Becoming a Reflective Educator: How to Build a Culture of Inquiry in the Schools (Second Edition), (Chinese edition). China Light Industry Press, 24-25. 